\title{
Linking the soil moisture distribution pattern to dynamic processes along slope transects in the Loess Plateau, China
}

\author{
Shuai Wang • Bojie Fu • Guangyao Gao • \\ Ji Zhou • Lei Jiao • Jianbo Liu
}

Received: 22 June 2015 / Accepted: 20 November 2015 /Published online: 30 November 2015

(C) Springer International Publishing Switzerland 2015

\begin{abstract}
Soil moisture pulses are a prerequisite for other land surface pulses at various spatiotemporal scales in arid and semi-arid areas. The temporal dynamics and profile variability of soil moisture in relation to land cover combinations were studied along five slopes transect on the Loess Plateau during the rainy season of 2011. Within the 3 months of the growing season coupled with the rainy season, all of the soil moisture was replenished in the area, proving that a type stability exists between different land cover soil moisture levels. Land cover combinations disturbed the trend determined by topography and increased soil moisture variability in space and time. The stability of soil moisture resulting from the dynamic processes could produce stable patterns on the slopes. The relationships between the mean soil moisture and vertical standard deviation (SD) and coefficient of variation (CV) were more complex, largely due to the fact that different land cover types had distinctive vertical patterns of soil moisture. The spatial SD of each layer had a positive correlation and the spatial CV exhibited a negative correlation with the increase in mean soil moisture. The soil moisture
\end{abstract}

S. Wang $(\bowtie) \cdot$ B. Fu $\cdot$ G. Gao $\cdot$ J. Zhou $\cdot$ L. Jiao $\cdot$ J. Liu State Key Laboratory of Urban and Regional Ecology, Research Center for Eco-Environmental Sciences, Chinese Academy of Sciences, PO Box 2871, Beijing 100085, China

e-mail: shuaiwang@rcees.ac.cn

B. Fu

e-mail: bfu@rcees.ac.cn

S. Wang · B. Fu • G. Gao · J. Zhou $\cdot$ L. Jiao · J. Liu Joint Center for Global Change Studies, Beijing 100875, China stability implies that sampling comparisons in this area can be conducted at different times to accurately compare different land use types.

Keywords Soil hydrology · Land use · Vegetation restoration $\cdot$ Hydrological processes $\cdot$ Re-vegetated catchment

\section{Introduction}

Soil moisture pulses triggered by rainfall are a prerequisite for biological and other land surface pulses at various spatiotemporal scales in arid and semi-arid areas (Schwinning and Sala 2004). An understanding of the coupling responses between land cover types and soil moisture is essential to determine the impact of various land uses on hydrological, ecological, and biogeochemical processes at different spatiotemporal scales ( $\mathrm{Li}$ 2011). Thus, the complex spatiotemporal patterns and variability of soil moisture content have been widely investigated, at various scales, by hydrologists and ecologists in recent decades (Chen et al. 2007; Fu et al. 2003; Hu et al. 2009; Qiu et al. 2001a, b, 2003; Western et al. 2004; Gao et al. 2011).

In arid and semi-arid areas, the existence and development of vegetation largely depend on soil moisture availability. In turn, different land cover types affect the mutually interacting hydrologic processes, especially infiltration and evapotranspiration (Fu et al. 2003; Wang et al. 2012; Wang et al. 2013), resulting in various characteristics of soil moisture dynamics (Qiu et al. 
2001a, b, 2003). Chen et al. (2007) evaluated the relationship between land cover types and soil moisture dynamics in the Loess Plateau area for five vegetation types and found that soil water loss occurred during the growing season, and the moisture was not fully replenished from rainfall during the rainy season. The soil moisture content for land covered by different vegetation types in the semiarid area of the Loess Plateau has been well studied and documented during the past few decades (Qiu et al. 2001a; Fu et al. 2003; Chen et al. 2007; Wang et al. 2012, 2013). The studies have indicated that bare soils usually have higher soil moisture content than vegetated soils, and that annual crops and grasses have higher soil moisture content than forests (Qiu et al. 2003).

Based on knowledge of the effects of various types of land use on soil moisture dynamics, Fu et al. (2003) analyzed soil moisture variations in relation to land use patterns using seven types and five combinations of land use type and soil dynamics. They indicated that different hydrological responses with regard to soil moisture along a slope could be created by altering the land use arrangement. This pattern, in combination with a contrasting hydrological response, such as that provided by a fallow land-shrubland-intercropping land-woodland structure, would lead to discontinuous runoff over a slope and thus better control water and soil erosion. The landscape pattern determines the ecological processes (Wu and Hobbs 2002). Fu et al. (2009) selected three land-use combinations on a hill slope to study their relationship with soil erosion and provided an important basis for the optimization of land use combinations to control soil erosion on slopes, which led to other important ecological benefits. However, the available data regarding the temporal dynamic relationship between land cover patterns and ecological processes is still not comprehensive enough.

The vertical profile distribution is also an important aspect of soil moisture characteristics. For example, the formation of dry soil layers is a specific hydrological phenomena in semi-arid regions of the Loess Plateau in China (Chen et al. 2008; Wang et al. 2010a, b). Qiu et al. (2001b) and Fu et al. (2003) suggested that the timeaveraged soil moisture content can be classified into either a decreasing, waving, or increasing type. Chen et al. (2007) discovered four patterns of vertical profile distribution (inclined I-shape, near L-shape, L-shape, and near I-shape) according to the integrated functions of transpiration, soil evaporation, and rainfall. These different vertical profiles directly determined the spatiotemporal dynamic characteristics of different layers of moisture and indirectly determined the average moisture content.

The relationship between mean moisture content and spatial variability is influenced by the factors we noted above, i.e., land cover types and their different combinations and the different vertical profile distributions (Gao et al. 2011). The spatiotemporal correlations between soil moisture variability and mean moisture content have been examined extensively in various environmental contexts. However, there is no consensus to the results (Vereecken et al. 2007). Some studies have found increases in the standard deviation (SD) of soil moisture with reductions in the mean moisture content (Brocca et al. 2007; Hupet and Vanclooster 2002), while others have found the opposite (Famiglietti et al. 1998; Martinez-Fernandez and Ceballos 2003). Recent studies have found that the SD and mean moisture content display a convex upward relationship (Brocca et al. 2010; Gao et al. 2011).

The "Grain-for-Green" project was initiated in 1999 throughout the Loess Plateau. As a result of this initiative, about $24 \%$ of the erosion area has been controlled, and vegetation cover has increased from $6.5 \%$ in the 1970 s to $11 \%$ in 1995 and $51.13 \%$ in 2010 (Wang et al. 2012). Most of the farmed slopes consist of planted trees and shrubs. Some farmlands have been abandoned and have developed into grass and subshrub communities. With the development and succession of these artificial vegetation types, their impacts on local hydrological processes are constantly adjusting and changing. Thus, the effects of land cover types and their various combinations warrant further attention.

The objectives of the study were to characterize: (i) the spatiotemporal distributions of soil moisture and its variation in three soil layers $(0-20,20-80$, and $80-180 \mathrm{~cm}$; defined here as the surface, middle, and deep layers, respectively) in the rainy season and (ii) the relationships between moisture content in the three layers and land cover types and different combinations. The overall aim was to link the soil moisture patterns with dynamic processes, also taking into account the vertical variations in a revegetated area of the Loess Plateau in China.

\section{Materials and methods}

Site description

The study was performed in the Yangjuangou catchment $\left(36^{\circ} 42^{\prime} \mathrm{N}, 109^{\circ} 31^{\prime} \mathrm{E}\right)$ located in the central part of the 
Loess Plateau (Fig. 1), which is a typical loess gully and hilly area with elevations ranging from 1050 to $1298 \mathrm{~m}$ (Liu et al. 2011; Wang et al. 2012, 2013). This catchment has a total area of $2.02 \mathrm{~km}^{2}$, with a gully density of $2.74 \mathrm{~km} \mathrm{~km}^{-2}$, and with slope gradients ranging from 10 to $30^{\circ}$. The catchment has a semi-arid continental climate with a mean annual precipitation of $535 \mathrm{~mm}$ and a mean air temperature of $10.6^{\circ} \mathrm{C}$ over the past 20 years. The rainfall is concentrated mainly between June and September and has a large inter-annual variation. The growing season for most deciduous plant species ranges from April to October. The soil in the study area is derived mainly from loess and has a depth of 50$200 \mathrm{~m}$ depending on the topography of the exact location where it is found. The loess in this area usually has a composition of more than $50 \%$ silt $(0.002-0.05 \mathrm{~mm})$ and less than $20 \%$ clay $(<0.002 \mathrm{~mm})$, with a porosity of approximately $50 \%$. The gravimetric field capacity and soil water content at the wilting point are 20-24\% and 3-6\%, respectively (Du et al. 2011).

The dominant land use in the Yangjuangou watershed was croplands before the 1980s. The revegetation process began on some infertile and steep arable lands with a low crop yield in the 1980s. Since 1999, driven by the implementation of the Grain-for-Green project, most of the cultivated land on steep slopes was gradually abandoned, with natural and artificial revegetation subsequently occurring. The current major vegetation types appeared at different stages of the restoration, under varying soil conditions. Grass and forest occupy most of the hillslopes and shrubs dominate the bottoms of the north-facing slopes. The major forest species that has been introduced into the Yangjuangou catchment is acacia (Robinia pseudoacacia), which was planted either in the 1980s or after 1999. Artemisia scoparia, Stipa bungeana, and Andropogon are the dominant subshrub and grass species. Spiraea pubescens and Hippophae rhamnoide are the major shrub species.

Soil moisture sampling transects and soil moisture sampling

To sample soil moisture levels, five slope transects (slopes 1, 2, 3, 4, and 5; Fig. 1) were established, with lengths of approximately 350, 300,300, 400, and $400 \mathrm{~m}$, respectively. There were $11,9,9,12$, and 11 sampling points along the transects of slopes 1, 2, 3, 4, and 5, respectively (Fig. 1). Soil moisture was sampled at these points at depths of $0-180 \mathrm{~cm}$ at $10-\mathrm{cm}$ intervals during the period from July 11 to October 2, 2011.

Throughout the entire sampling period, there were 10 sampling periods, and 9664 measurements were taken in total. Note that soil moisture was not measured along the transect of slopes 2 and 3 on August 21, 2011. On each sampling occasion, soil moisture was sampled within 4 min. Because the samples were taken over such short periods of time, the temporal variation of soil moisture was expected to be negligible. A portable automatic weather station was located on the relatively planar gully upland, close to the sampling transects. In total, $362 \mathrm{~mm}$ of precipitation was recorded during the study period. Soil moisture values for all depths were sampled using a portable time domain reflectometry system (TRIME-PICO IPH/T3; IMKO, Ettlingen, Germany), consisting of a TRIMEIPH probe, a TRIME-Data Pilot data logger, and fiber glass access tubes $(\varphi=40 \mathrm{~mm})$. Instead of using the original accessories for installing tubes, a hand auger $(\varphi=45 \mathrm{~mm})$ was used to install fiber glass access tubes. To facilitate the installation of the tubes, the relief at some sampling points was disturbed slightly. The TRIMETDR system has been shown to provide accurate soil moisture measurements in the Loess Plateau region after local calibration (Li et al. 2005; Gao et al. 2011).

We selected five sites with typical land cover types: a tree site (R. pseudoacacia), shrub site (S. pubescens), subshrub site (A. scoparia), grass site (Andropogon), and crop site (Zea mays) to observe the soil moisture dynamics every $10 \mathrm{~min}$, using a $\mathrm{H} 21$ soil moisture and temperature logger system, with six S-SMC-M005 soil moisture smart sensors (Decagon Devices Inc., Pullman, WA, USA) at depths of 10, 20, 40, 60, 80, and $100 \mathrm{~cm}$ below the land surface (Wang et al. 2012, 2013) to link the soil moisture distribution pattern with dynamic processes. The data for the tree site was missing from August 9 due to the data logger being damaged, while data for the shrub site were missing from August 8 to 15 .

\section{Topographical attributes and the land cover types}

The five slope transects had different land cover combinations (land cover types from the foot to the top of the hillslope). Slope 1 was young plantation + old plantation + grass; slope 2 was subshrub + young plantation + grass; slope 3 was old plantation + young plantation + grass; slope 4 was shrub + grass + old 

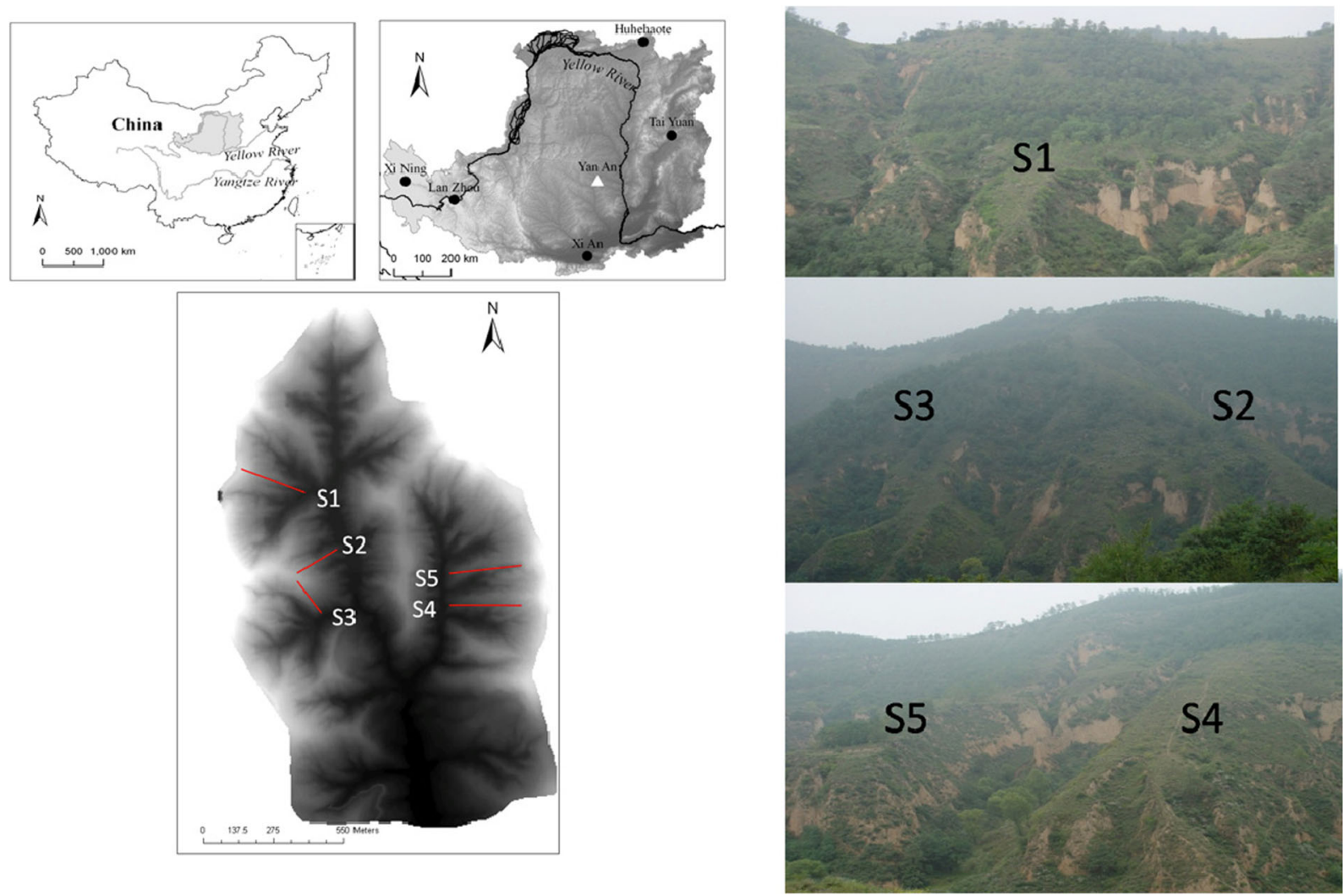

Fig. 1 The general location of Yangjuangou watershed and pictures of the sampling sites

plantation; slope 5 was young plantation + shrub + grass (Table 1). The grasses were mainly Artemisia Linn, couch grass, and small weeds. The shrubs were Prunus armeniaca and $H$. rhamnoides in the mature forest and $R$. pseudoacacia in the young forest. The shape and gradient of slopes 1,4 , and 5 were identical, but slope 1 had the opposite aspect of the other two slopes. Slopes 2 and 3 also had similar shapes and gradients, but a different aspect (Fig. 1).

\section{Calculation of variables}

We denoted the $0-10,10-20 \ldots 170-180 \mathrm{~cm}$ layers as $\mathrm{d} 1$, $\mathrm{d} 2 \ldots \mathrm{d} 18$, respectively, and the soil moisture content in these layers was calculated as follows (Gao et al. 2011):

(a) Soil moisture profiles at a given sampling time for the four depths considered:

$$
\theta_{\text {total }, j, t}=\frac{1}{18} \sum_{i=1}^{18} \theta_{d i, j, t},
$$

$$
\begin{aligned}
& \theta_{20, j, t}=\frac{1}{2} \sum_{i=1}^{2} \theta_{d i, j, t}, \\
& \theta_{80, j, t}=\frac{1}{6} \sum_{i=1}^{6} \theta_{d i, j, t}, \\
& \theta_{180, j, t}=\frac{1}{10} \sum_{i=1}^{10} \theta_{d i, j, t}
\end{aligned}
$$

where $d i$ denotes the soil layer, $j$ the sampling point, and $t$ the sampling time.

(b) Mean moisture profiles for all locations at a given sampling time for the four layers considered:

$\bar{\theta}_{\text {total }, t}=\frac{1}{52} \sum_{j=1}^{52} \theta_{\text {total }, j, t}$

$\bar{\theta}_{20, t}=\frac{1}{52} \sum_{j=1}^{52} \theta_{20, j, t}$ 
Table 1 Topographical attributes and land cover types of the sample sites

\begin{tabular}{|c|c|c|c|c|c|c|}
\hline Slope & Site & Aspect & Cos (aspect) & Gradient $\left(^{\circ}\right)$ & Cover type & Comment \\
\hline $\mathrm{S} 1$ & A1 & East & -0.173 & 21 & Young plantation & $<5$ years, bottom of the slope \\
\hline S1 & $\mathrm{A} 2$ & East & -0.173 & 21 & Young plantation & $<5$ years \\
\hline $\mathrm{S} 1$ & A3 & East & -0.173 & 21 & Young plantation & $<5$ years \\
\hline S1 & A4 & East & -0.173 & 16 & Young plantation & $<5$ years \\
\hline $\mathrm{S} 1$ & A5 & East & -0.173 & 22 & Young plantation & $\begin{array}{l}<5 \text { years, more dense, transition } \\
\text { zone between young } \\
\text { plantation and old plantation }\end{array}$ \\
\hline $\mathrm{S} 1$ & A6 & East & -0.173 & 16 & Old plantation & $>25$ years \\
\hline $\mathrm{S} 1$ & A7 & East & -0.173 & 31 & Old plantation & $>25$ years \\
\hline $\mathrm{S} 1$ & A8 & East & -0.173 & 36 & Old plantation & $>25$ years \\
\hline S1 & A9 & East & -0.173 & 39 & Old plantation & $>25$ years, gully bank \\
\hline S1 & $\mathrm{A} 10$ & East & -0.173 & 39 & Old plantation & $>25$ years, gully bank \\
\hline $\mathrm{S} 1$ & A11 & - & - & 0 & Grassland & Mountaintop \\
\hline $\mathrm{S} 2$ & B1 & Northeast & 0.574 & 16 & Subshrub & Bottom of the slope \\
\hline S2 & B2 & Northeast & 0.574 & 12 & Subshrub & - \\
\hline S2 & B3 & Northeast & 0.574 & 14 & Shrub & - \\
\hline S2 & B4 & Northeast & 0.707 & 36 & Young plantation & Higher and with dense herbs \\
\hline S2 & B5 & Northeast & 0.707 & 34 & Young plantation & Higher and with dense herbs \\
\hline S2 & B6 & Northeast & 0.707 & 27 & Young plantation & Dense herbs \\
\hline S2 & B7 & Northeast & 0.707 & 26 & Young plantation & Dense herbs \\
\hline $\mathrm{S} 2$ & B8 & Northeast & 0.707 & 24 & Grassland & Sparse \\
\hline $\mathrm{S} 2$ & B9 & Northeast & 0.707 & 34 & Grassland & - \\
\hline S3 & $\mathrm{C} 1$ & Southeast & -0.706 & 28 & Old plantation & $>30$ years \\
\hline S3 & $\mathrm{C} 2$ & Southeast & -0.706 & 33 & Old plantation & $>30$ years \\
\hline S3 & $\mathrm{C} 3$ & Southeast & -0.706 & 37 & Old plantation & $>30$ years \\
\hline S3 & $\mathrm{C} 4$ & Southeast & -0.706 & 38 & Old plantation & $>30$ years \\
\hline S3 & $\mathrm{C} 5$ & Southeast & -0.706 & 32 & Old plantation & $>30$ years \\
\hline S3 & C6 & Southeast & -0.706 & 21 & Old + young plantation & - \\
\hline S3 & $\mathrm{C} 7$ & Southeast & -0.706 & 12 & Grassland & Sparse \\
\hline S3 & $\mathrm{C} 8$ & Southeast & -0.706 & 10 & Grassland & Sparse \\
\hline S3 & C9 & Southeast & -0.706 & 8 & Grassland & Dense \\
\hline S4 & D1 & Southwest & -0.344 & 8 & Shrub & Sparse \\
\hline S4 & D2 & Southwest & -0.344 & 16 & Shrub & Sparse \\
\hline S4 & D3 & Southwest & -0.344 & 21 & Shrub & Sparse \\
\hline S4 & D4 & Southwest & -0.344 & 16 & Shrub & Sparse \\
\hline S4 & D5 & Southwest & -0.344 & 8 & Orchard & \\
\hline S4 & D6 & Southwest & -0.344 & 16 & Grassland & Sparse \\
\hline S4 & D7 & Southwest & -0.344 & 26 & Subshrub + grassland & $\begin{array}{l}\text { Transition zone between } \\
\text { grassland and old plantation }\end{array}$ \\
\hline S4 & D8 & Southwest & -0.344 & 34 & Old plantation & $>30$ years \\
\hline S4 & D9 & Southwest & -0.344 & 35 & Old plantation & $>30$ years \\
\hline S4 & D10 & Southwest & -0.344 & 35 & Old plantation & $>30$ years \\
\hline S4 & D11 & Southwest & -0.344 & 35 & Old plantation & $>30$ years, gully bank \\
\hline S4 & D12 & - & - & - & Grassland & Mountaintop \\
\hline S5 & E1 & Southwest & -0.344 & 8 & Young plantation & Terrace land \\
\hline
\end{tabular}


Table 1 (continued)

\begin{tabular}{|c|c|c|c|c|c|c|}
\hline Slope & Site & Aspect & Cos (aspect) & Gradient $\left(^{\circ}\right)$ & Cover type & Comment \\
\hline S5 & E2 & Southwest & -0.344 & 5 & Young plantation & Terrace land \\
\hline S5 & E3 & Southwest & -0.344 & 5 & Young plantation & Terrace land \\
\hline S5 & E4 & Southwest & -0.344 & 0 & Young plantation & Terrace land \\
\hline S5 & E5 & Southwest & -0.344 & 0 & Young plantation & Terrace land \\
\hline S5 & E6 & Southwest & -0.344 & 0 & Young plantation & Terrace land \\
\hline S5 & E7 & Southwest & -0.344 & 0 & Young plantation & Terrace land, with silt pit \\
\hline S5 & E8 & Southwest & -0.344 & 0 & Shrub & Dense \\
\hline S5 & E9 & Southwest & -0.344 & 0 & Shrub & Dense \\
\hline S5 & E10 & Southwest & -0.344 & 0 & Young plantation & Terrace land, with silt pit \\
\hline S5 & E11 & - & - & - & Grassland & Mountaintop \\
\hline
\end{tabular}

$\bar{\theta}_{80, t}=\frac{1}{52} \sum_{j=1}^{52} \theta_{80, j, t}$

$\bar{\theta}_{180, t}=\frac{1}{52} \sum_{j=1}^{52} \theta_{180, j, t}$

We calculated the mean moisture profiles for each slope at a given sampling time for the four layers considered using the same equations.

(c) Mean moisture profiles derived from the combined soil moisture dataset for the four layers considered:

$\bar{\theta}_{\text {total }}=\frac{1}{T} \sum_{t=1}^{T} \bar{\theta}_{\text {total }, t}$

$\bar{\theta}_{20}=\frac{1}{T} \sum_{t=1}^{T} \bar{\theta}_{20, t}$

$\bar{\theta}_{80}=\frac{1}{T} \sum_{t=1}^{T} \bar{\theta}_{80, t}$

$\bar{\theta}_{180}=\frac{1}{T} \sum_{t=1}^{T} \bar{\theta}_{180, t}$

\section{Results}

Comparison of mean moisture and its spatiotemporal variability

Table 2 shows the summary statistics of the soil moisture content for the four layers considered. These statistics were derived from all measurements. Because sampling was concentrated in the rainy season, the soil was driest in the $80-180-\mathrm{cm}$ layer and wettest in the $0-20$-cm layer. The coefficient of variation (CV) and skewness were highly dependent on soil depth, with both decreasing with increasing depth, while the SD and kurtosis had no monotonous relationship with soil depth.

Figure 2 shows the temporal dynamics of precipitation, the mean, and the spatial and vertical SD and CV of the moisture content at the four depths, which is a summary of data from the combined soil moisture dataset for all four layers. Overall, the mean moisture content responded positively to precipitation at all depths during the study period. Surface (0- to $20-\mathrm{cm}$ depth) soil moisture responded to precipitation and evapotranspiration more quickly and appeared over a larger dynamic range, while the middle layer (20- to 80cm depth) was relatively stable. Deep layers (80- to 180 $\mathrm{cm}$ depth), as well as the total average soil moisture content, displayed a steady growth trend during the study period. The spatial SD of each layer had a positive correlation, and the spatial CV had a negative correlation with the increase in mean soil moisture. The relationships between mean soil moisture and vertical SD and CV were more complex. The vertical SD of middle, deep, and all layers combined increased with the mean 
Table 2 Summary statistics of soil moisture at selected depths derived from all measurements

\begin{tabular}{lccccccc}
\hline Depth & Mean & SD & CV & Skewness & Kurtosis & Maximum & Minimum \\
\hline Total & 12.39 & 1.80 & 0.15 & 0.26 & -0.08 & 24.07 & 3.21 \\
$0-20 \mathrm{~cm}$ & 17.52 & 5.30 & 0.30 & -0.75 & -0.15 & 27.70 & 1.55 \\
$20-80 \mathrm{~cm}$ & 14.91 & 4.74 & 0.32 & -0.14 & -0.64 & 25.99 & 3.15 \\
$80-180 \mathrm{~cm}$ & 9.81 & 4.88 & 0.50 & 0.51 & -0.09 & 23.73 & 0.18 \\
\hline
\end{tabular}

soil moisture, while the surface layer decreased. The total vertical $\mathrm{CV}$ had a positive correlation, and the surface layer had a negative correlation with the mean soil moisture; however, there were no constant relationships in the middle and deep layers.

The correlation between mean soil moisture content and both SD and CV (spatial and vertical), using data from the soil moisture datasets at every site, had the same trend as that from the combined dataset.
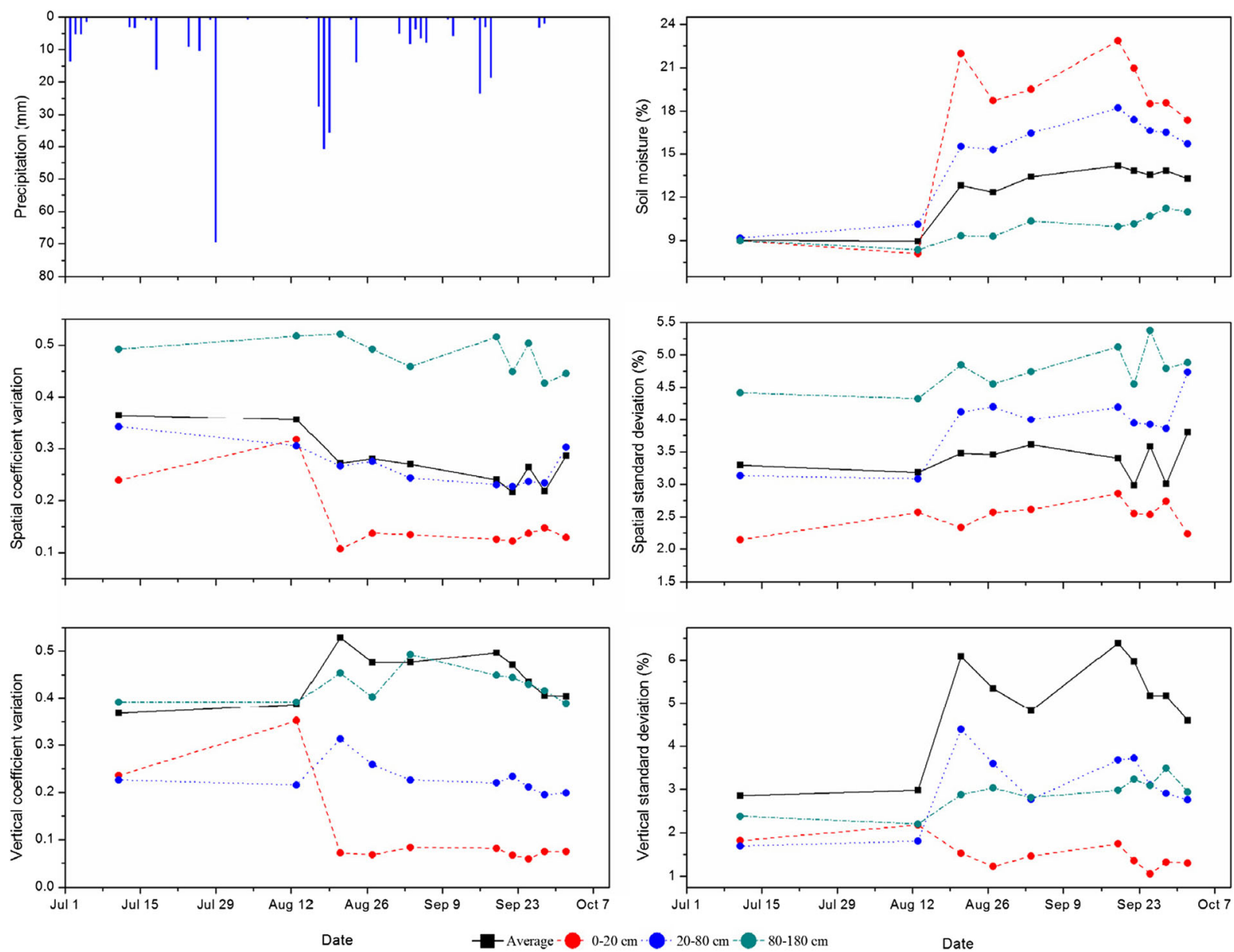

Fig. 2 Time series of daily precipitation, and the mean, spatial, and vertical standard deviation and coefficient of variation of moisture content throughout the whole study period

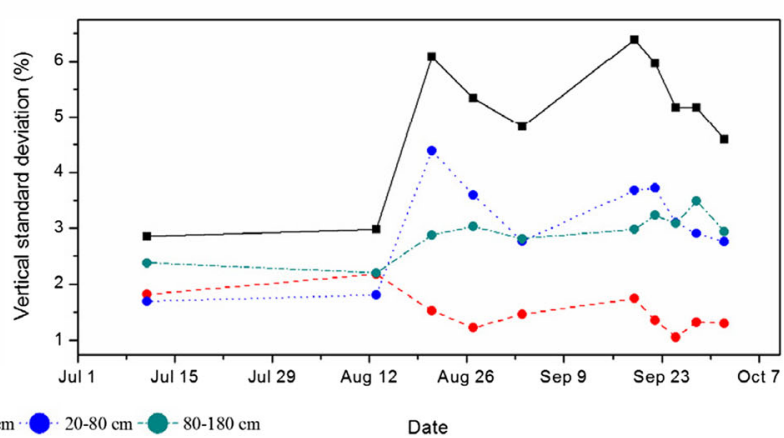

Empirically, fitted curves for the SD and CV values versus the mean moisture content are shown in Fig. 3 and used the fitting functions defined by Famiglietti et al. (2008) as follows:

$$
C V=A \cdot \exp (-B \cdot \bar{\theta}), \quad S D=A \cdot \bar{\theta} \cdot \exp (-B \cdot \bar{\theta})
$$

where $A$ and $B$ are model parameters, and $\bar{\theta}$ is the mean moisture content. Note that the SD versus

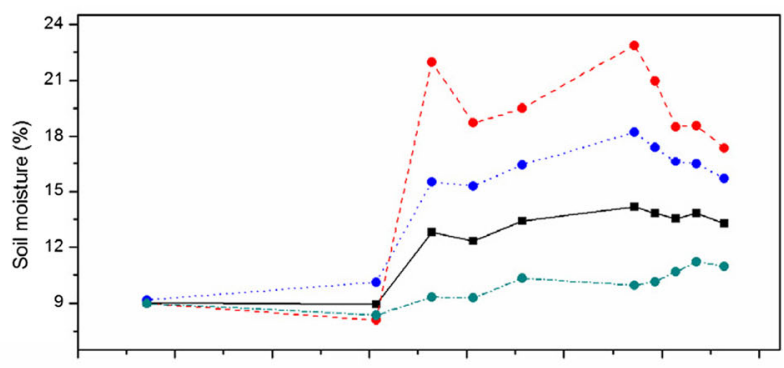



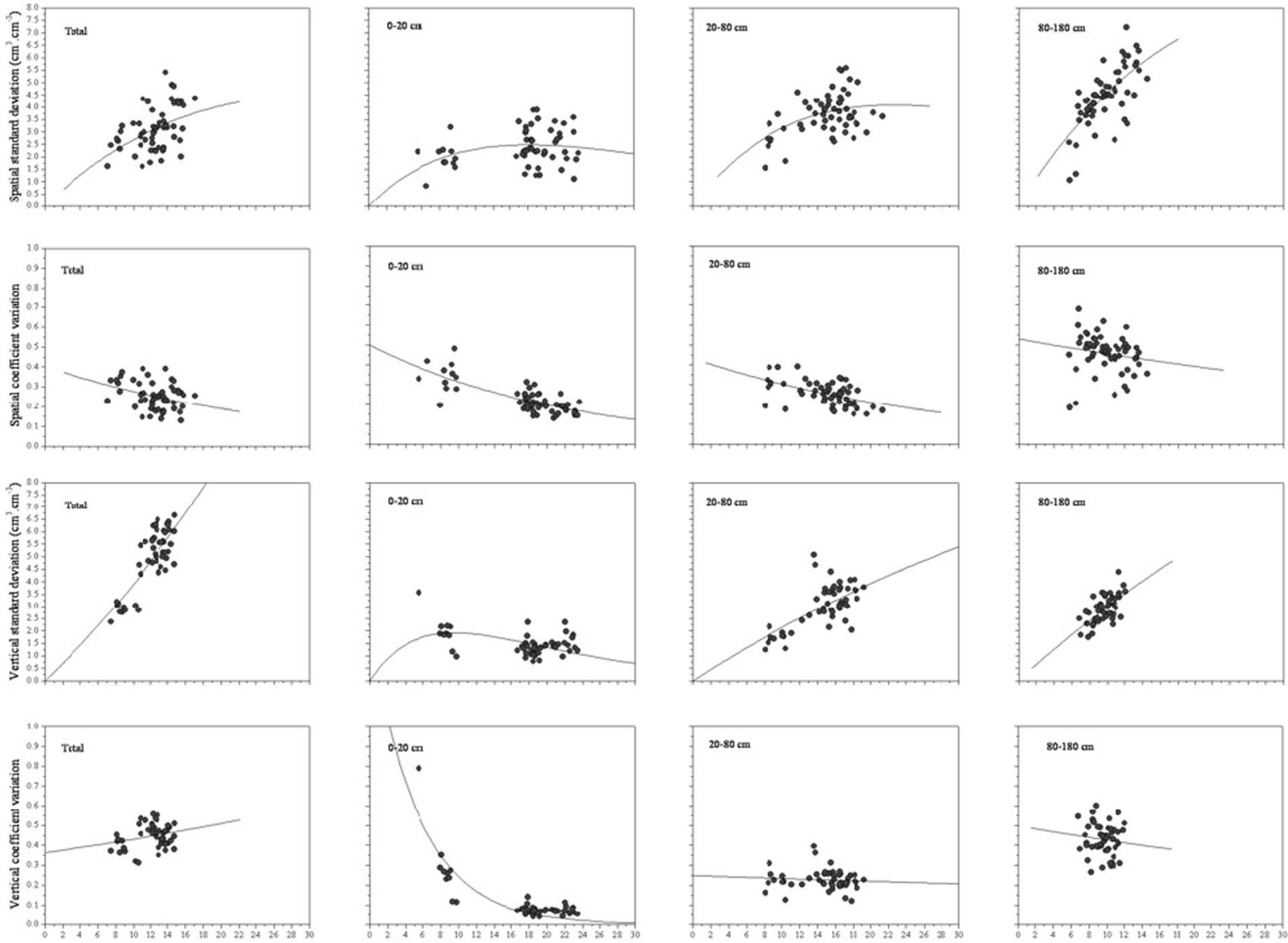

Fig. 3 Relationships between mean soil moisture and spatial and vertical standard deviation and coefficient of variation for the average of all layers (total), 0-20 cm-layer, 20-80-cm layer, and the 80-180-cm layer

mean moisture content fitting function is derived from the corresponding CV function. Tables 3 and 4 show the fitting regression results using the equation above. Unfortunately, among the lower $R^{2}$ values, these exponential decay functions do not comprehensively capture the relationship between $\mathrm{SD}$ and $\mathrm{CV}$ with mean moisture content.

Table 3 Fitting results for spatial CV and SD versus mean moisture content

\begin{tabular}{lllll}
\hline Soil depth & $\mathrm{A}$ & $\mathrm{B}$ & $R^{2}(\mathrm{CV})$ & $R^{2}(\mathrm{SD})$ \\
\hline Total & 0.356 & 0.028 & 0.103 & 0.165 \\
$0-20 \mathrm{~cm}$ & 0.499 & 0.046 & 0.576 & 0.061 \\
$20-80 \mathrm{~cm}$ & 0.432 & 0.035 & 0.235 & 0.262 \\
$80-180 \mathrm{~cm}$ & 0.585 & 0.024 & 0.010 & 0.485 \\
\hline
\end{tabular}

Mean moisture content comparison between slopes

Figure 4 shows that the differences between the surface soil moisture levels of the five slope transects were very small, particularly after they had been replenished by precipitation. The mean soil moisture level fluctuated in the surface layer. Soil

Table 4 Fitting results for spatial CV and SD versus mean moisture content

\begin{tabular}{lllll}
\hline Soil depth & A & B & $R^{2}(\mathrm{CV})$ & $R^{2}(\mathrm{SD})$ \\
\hline Total & 0.342 & -0.013 & 0.049 & 0.655 \\
$0-20 \mathrm{~cm}$ & 1.489 & 0.18 & 0.006 & 0.755 \\
$20-80 \mathrm{~cm}$ & 0.233 & 0.008 & 0.010 & 0.444 \\
$80-180 \mathrm{~cm}$ & 0.328 & 0.009 & 0.008 & 0.403 \\
\hline
\end{tabular}



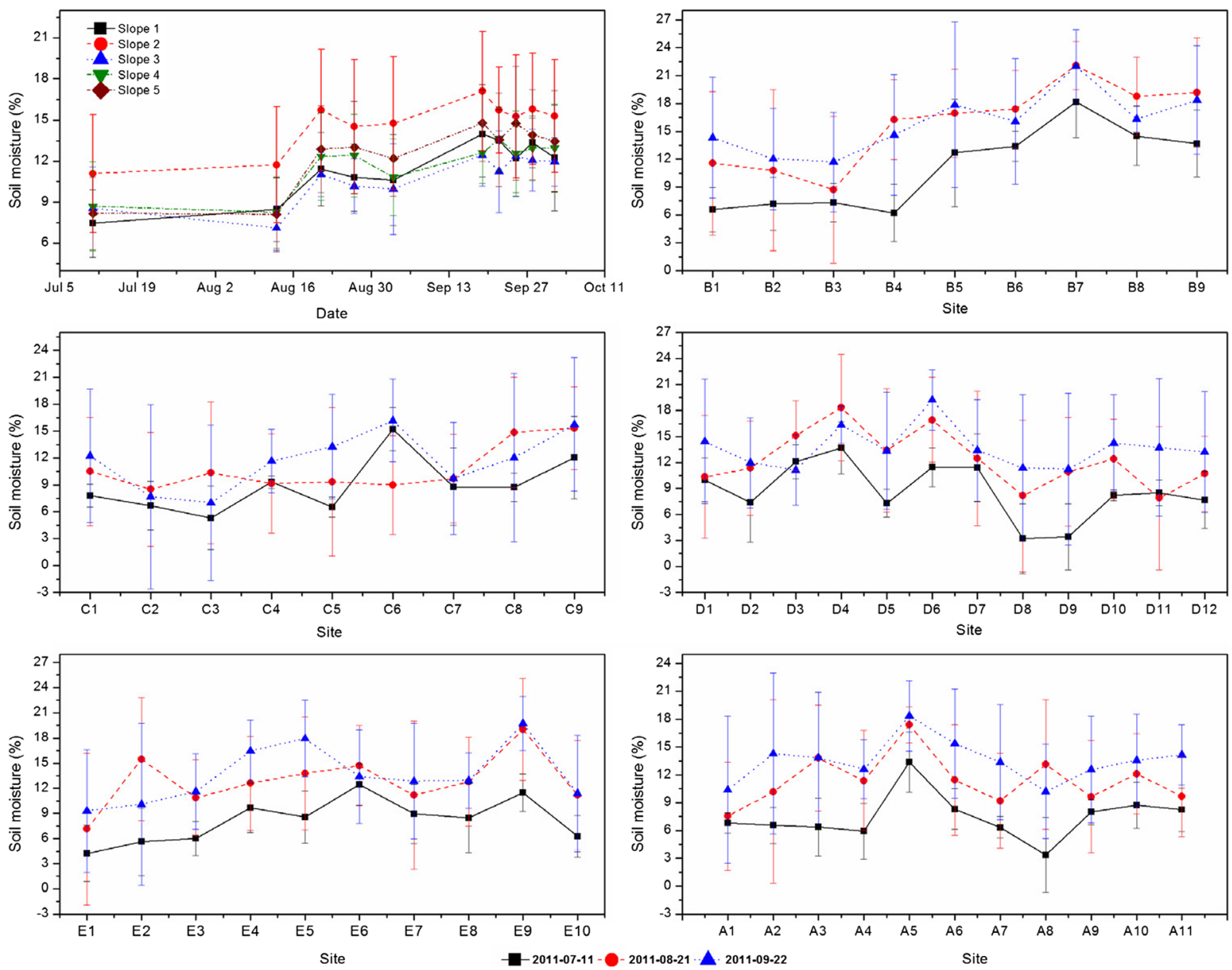

Fig. 4 The temporal dynamics of the mean soil moisture of the five slopes and the total average soil moisture content along the five slope transects for three sampling periods

moisture in the middle layer markedly increased due to the frequent precipitation at the end of August and early September. There was a homogenization effect on the mean soil moisture content of the five slope transects. Precipitation had no significant effect on the soil moisture of the deep layer. There was a similar strength of correlation between the mean soil moisture content of the five slope transects in the middle and deep layers. The mean soil moisture content in slope 1 was always higher than the other four slopes during the study period. In slope 4, the mean soil moisture content was relatively smaller in the middle and deep layers, and in slope 5 , it became absolutely smaller. The total average soil moisture regime was mainly controlled by the middle and deep layers.
Down slope soil moisture patterns

Figure 4 also shows the transect profiles of soil moisture on the five slopes during three sample periods. The combination of land cover types on the slope had an impact on soil moisture content. Where the land cover combination was young plantation + old plantation + grass, the general trend in moisture varied and could be described as an inverted ' $\mathrm{V}$ '. Both the young plantation in the lower slope and the old plantation in the upper slope positions produced a lower soil moisture content, while the transitional zone of young plantation and old plantation on the middle slope generated a higher moisture content. However, the moisture content sampled on August 21 and September 22 at the surface, and in the middle, two layers were contrary to this trend. 
Where the land cover combination from the lower slope to the upper slope was a mixture of shrub + young plantation + grass, the trend in the moisture content at the surface and in the middle layer was irregular. The moisture in the deep layer and the total average moisture were both obviously dependent on the topography and land cover types. Initially, the moisture decreased under shrub cover, then increased in the young forest, and ultimately reduced under grass cover.

On slope 3, the land cover combination from the lower to upper slope was a mixture of old plantation + young plantation + grass, and the down slope soil moisture pattern showed that the site contained a combination of young and old plantation. This combination of young and old plantation had the highest moisture content, followed by a combination of grass and old plantations. However, this trend was not apparent in the surface and middle layers.

On slope 4, where the land cover from the lower to upper slope was shrub + grass + old plantation, there was a phenomenon observed where once moisture entered the old plantation, the soil moisture content in all layers was significantly reduced. This pattern indicated that moisture was drawn more quickly in the old plantation than other land cover types.

The land cover combination from the lower slope to the upper slope for slope 5 was young plantation+ shrub + grass. All of the young plantations were formerly terrace land, some of them with silt pits. The results from slope 5 show that the site of the young plantation had a higher soil moisture than the land under shrubs and grass, and an increasing trend was also observed from the lower to upper slope (Fig. 4).

Linking the soil moisture pattern with dynamic processes

The soil moisture dynamic processes for different land cover types clearly showed they had different water infiltration and evapotranspiration characteristics and resulted in different soil moisture vertical profiles (Fig. 5). The mean soil moisture content profiles of the five vegetation types were in the order of crop $>$ grass $>$ subshrub $>$ tree $>$ shrub, and this relationship was stable over time. The soil moisture was mainly replenished by three to four heavy precipitation events during July and August. The subshrub site had the highest total infiltration following precipitation during the study period. In periods of both relatively low and high water soil moisture content, subshrubs lost the largest amount of water of all vegetation types.

\section{Discussion}

Effect of land cover type on soil moisture

Many of the factors that influence the spatial and temporal variances of soil moisture have been studied previously (Qiu et al. 2001a, b, 2003; Fu et al. 2003; Lin et al. 2006; Brocca et al. 2007, 2008; Chen et al. 2007). In this revegetated area, the different land cover types were the main control on moisture distributions. This combination of land cover types and revegetation has also been extensively studied (Yang and Tian 2004; Shangguan and Zheng 2006; Chen et al. 2008; Ran et al. 2008, Hu et al. 2009; Wang et al. 2010a, b, 2012, 2013). This has resulted in the acquisition of data regarding the mean soil moisture dynamic characteristics and the differences between slopes and downslope regions. Different land cover types had a different impact on the variation in mean soil moisture $(P<0.05)$. Of all the land cover types investigated here, the mean moisture content was highest in the soil of an abandoned orchard. This resulted from the construction of terraces and silt pits, as well as other soil and water conservation measures. The moisture content of the old plantation was the lowest of all the land cover types investigated, which is a common phenomenon throughout the Loess Plateau area. The soil moisture content values of grassland and young plantations were lower than those of the orchard and higher than the shrub land. This is consistent with the results of previous studies (Chen et al. 2010). However, for different soil depths, there were no significant differences between the surface $(0$ $20 \mathrm{~cm}$ ) layers of different land cover types. The most significant difference in mean moisture content was found for the deep ( $80-180 \mathrm{~cm}$ ) layer. This can be attributed to the fact that our samples were taken in the rainy season. After soil moisture had been replenished by concentrated rainfall, the differences between the soil moisture content of each land cover type decreased. It should be noted that annual precipitation is low in this area, and it is also concentrated in the growing season. The soil moisture content cannot increase the growing season. This led to an increase in the spatial SD, but the $\mathrm{CV}$ decreased as the moisture level increased. Within 3 months of the growing season, the precipitation was 

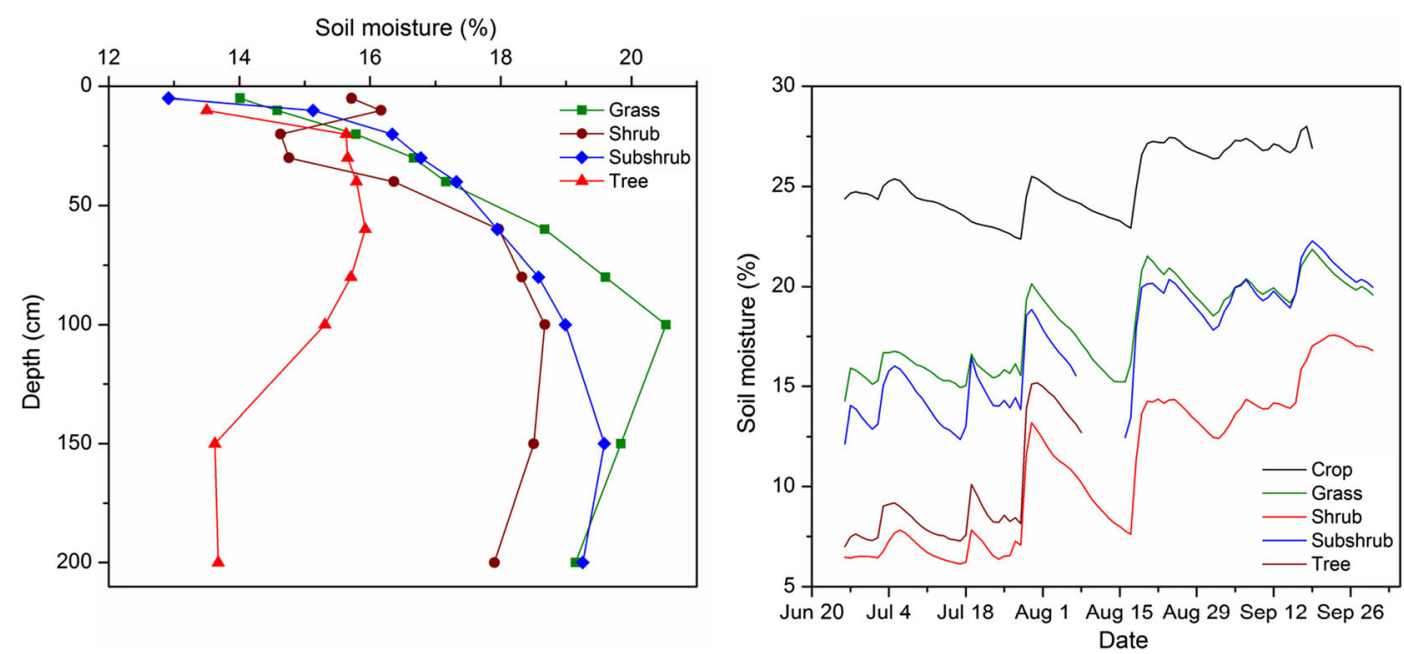

Fig. 5 Soil moisture vertical profiles of five type land cover types and their dynamics during the growing season

$362 \mathrm{~mm}$ and the soil moisture in the study area was still increasing. This implies that the current level of soil moisture can support vegetation growth. Some type of stability existed in the soil moisture level for the different types of land cover during the observation period and the rainy season.

Effect of land cover combination and soil moisture

Changes in the type of land cover and land cover combinations can also change the hydrological structure (Ludwig et al. 1995), influencing the biological and geomorphological pulse processes. Ludwig et al. (2005) studied the interactivity of the mosaic of land cover and runoff erosion for land use in arid and semiarid areas and concluded that local water and sediment redistribution was due to the existing vegetation pattern. Bedford and Small (2008) studied the spatial pattern of soil ecohydrological attributes in slope-alluvial soil in central New Mexico and found that the spatial pattern of vegetation determines the spatial pattern of soil properties. This study showed that grass land and young plantation on both the upper and lower slopes had higher moisture content. Wei et al. (2007) reported that soil water content was higher in the early stage of a tree plantation than in the late stage. It has also been shown that soil desiccation developed under a 28-year-old tree plantation (Zheng et al. 2008). The transition zones between an old and young plantation usually have significantly higher moisture content. In general, soil moisture is influenced jointly by soil properties and topography (Fu et al. 2003). The impact of topography was apparent, with slope 2 always having higher moisture content due to it being the only shaded slope. However, multiple land cover combinations disturbed this trend along the slope, and different combinations resulted in fluctuations in the soil moisture content from the lower to upper portion of the slope. Different land use or cover types increase the variability of soil moisture in space and time, but the type of stability of the soil moisture results in a pattern of stability that is often called temporal stability (Zhou et al. 2015). It is necessary to measure the temporal stability of the soil moisture content to identify representative locations in this revegetated, typically hilly-gully Loess Plateau catchment.

\section{Vertical profile variations of soil moisture}

Different land cover types resulted in distinctive vertical patterns of soil moisture. Fu et al. (2003) classified these patterns into three categories of increasing, decreasing, and waving types. The increasing type included the cropland, fallow land, intercropping land, and grassland. The waving type consisted of woodland and the orchard where soil moisture presented a high-low-high-lowhigh change in profile. The decreasing type included only shrub land. Differences in the distribution of roots and physical properties of the soil contributed to the difference in the variability of the profile of the soil moisture (Qiu et al. 2001b). These different vertical profiles were also apparent in this study, leading to a more complicated and irregular relationship between mean soil moisture content and the vertical SD and CV. 


\section{Conclusion}

The temporal dynamic and profile variability of the soil moisture level in relation to land cover types and their various combinations was studied at 52 locations on five different slopes at the Yangjuangou catchment on the Loess Plateau of China. Land cover types and their spatial combinations contributed to the variations in soil moisture content, along with rainfall, topography, and soil properties. During the growing season, coupled with the rainy season, the soil moisture content for all land cover types on the five slopes was replenished. Although the absolute moisture content increased during the study period, it was relatively low for some land cover types due to the higher evapotranspiration at the old plantation sites. The spatial SD of each layer had a positive correlation with the increase in the mean soil moisture, while the spatial CV had a negative correlation. The relationships between mean soil moisture content and the vertical SD and CV were more complex, resulting from different land cover types that had distinctive vertical patterns of soil moisture. Land cover type clearly had an impact on mean soil moisture variations. The mean moisture content of the abandoned orchard was the highest of all the land cover types investigated. The moisture content of the old plantation was the lowest. The values for grassland and the young plantation were lower than those for the orchard and higher than for the shrubs. Multiple land cover combinations disturbed the trend determined by topography and resulted in fluctuations in the soil moisture content from the lower to upper slope.

Acknowledgements This work was funded by the National Natural Science Foundation of China (No. 41390464, 41401027).

\section{References}

Bedford, D. R., \& Small, E. E. (2008). Spatial patterns of ecohydrologic properties on a hillslope-alluvial fan transect, central New Mexico. Catena, 73, 34-48.

Brocca, L., Morbidelli, R., Melone, F., \& Moramarco, T. (2007). Soil moisture spatial variability in experimental areas of central Italy. Journal of Hydrology, 333, 356-373.

Brocca, L., Melone, F., \& Moramarco, T. (2008). On the estimation of antecedent wetness conditions in rainfall-runoff modelling. Hydrology Processes, 22, 629-642.

Brocca, L., Melone, F., Moramarco, T., \& Morbidelli, R. (2010). Spatial-temporal variability of soil moisture and its estimation across scales. Water Resources Research, 46, W02516. doi:10.1029/2009WR008016.

Chen, L. D., Huang, Z. L., Gong, J., Fu, B. J., \& Huang, Y. L. (2007). The effect of land cover/vegetation on soil water dynamic in the hilly area of the loess plateau, China. Catena, 70, 200-208.

Chen, H. S., Shao, M. A., \& Li, Y. Y. (2008). The characteristics of soil water cycle and water balance on steep grassland under natural and simulated rainfall conditions in the Loess Plateau of China. Journal of Hydrology, 360, 242-251.

Chen, L. D., Wang, J. P., Wei, W., Fu, B. J., \& Wu, D. P. (2010). Effects of landscape restoration on soil water storage and water use in the Loess Plateau Region, China. Forest Ecology and Management, 259, 1291-1298.

Du, S., Wang, Y. L., Kume, T., Zhang, J. G., Otsuki, K., Yamanaka, N., \& Liu, G. B. (2011). Sapflow characteristics and climatic responses in three forest species in the semiarid Loess Plateau region of China. Agricultural and Forest Meteorology, 151, 1-10.

Famiglietti, J. S., Rudnicki, J. W., \& Rodell, M. (1998). Variability in surface soil moisture content along a hillslope transect: Rattlesnake Hill, Texas. Journal of Hydrology, 210, 259281.

Famiglietti, J. S., Ryu, D., Berg, A. A., Rodell, M., \& Jackson, T. J. (2008). Field observations of soil moisture variability across scales. Water Resources Research, 44, W01423. doi:10.1029/ 2006WR005804.

Fu, B. J., Wang, J., Chen, L., \& Qiu, Y. (2003). The effects of land use on soil moisture variation in the Danangou catchment of the Loess Plateau, China. Catena, 54, 197-213. doi:10.1016/ S0341-8162(03)00065-1.

Fu, B. J., Wang, Y. F., Lu, Y. H., He, C. S., Chen, L. D., \& Song, C. J. (2009). The effects of land-use combinations on soil erosion: a case study in the Loess Plateau of China. Progress in physical geography, 33(6), 793-804.

Gao, X. D., Wu, P. T., Zhao, X. N., Shi, Y. G., Wang, J. W., \& Zhang, B. Q. (2011). Soil moisture variability along transects over a well-developed gully in the Loess Plateau, China. Catena, 87, 357-367.

Hu, W., Shao, M. A., Wang, Q. J., \& Reichardt, K. (2009). Time stability of soil water storage measured by neutron probe and the effects of calibration procedures in a small watershed. Catena, 79, 72-82.

Hupet, F., \& Vanclooster, M. (2002). Intraseasonal dynamics of soil moisture variability within a small agricultural maize cropped field. Journal of Hydrology, 261, 86-101.

Li, X. Y. (2011). Mechanism of coupling, response and adaptation between soil, vegetation and hydrology in arid and semiarid regions (in Chinese). Scientia sinica Terrae, 41, 1721-1730.

Li, X. Y., Bi, H. X., Diao, Y. M., Liu, L. F., Li, G. X., \& Li, J. (2005). The measurement principles of TRIME-TDR system and its application in Caijiachuan watershed of Loess Plateau, China. Science of Soil and Water Conservation, 3(1), 112-115 (In Chinese with English abstract).

Lin, H. S., Kogelmann, W., Walker, C., \& Bruns, M. A. (2006). Soil moisture patterns in a forested catchment: a hydropedological perspective. Geoderma, 131, 345-368.

Liu, Y., Fu, B. J., Lü, Y. H., Wang, Z., \& Gao, G. Y. (2011). Hydrological responses and soil erosion potential of abandoned cropland in the Loess Plateau. China, Geomorphology, 138, 404-414. 
Ludwig, B., Boiffin, J., Chaduf, J., \& Auzet, A. V. (1995). Hydrological structure and erosion damage caused by concentrated flow in cultivated catchments. Catena, 25, 227-52.

Ludwig, J., Wilcox, B., Breshears, D., Tongway, D., \& Imeson, A. (2005). Vegetation patches and runoff-erosion as interacting ecohydrological processes in semiarid landscapes. Ecology, 86, 288-97.

Martinez-Fernandez, J., \& Ceballos, A. (2003). Temporal stability of soil moisture in a largefield experiment in Spain. Soil Science Society of America Journal, 67, 1647-1656.

Qiu, Y., Fu, B. J., Wang, J., \& Chen, L. D. (2001a). Soil moisture variation in relation to topography and land use in a hillslope catchment of the Loess Plateau, China. Journal of Hydrology, 240(3-4), 243-263.

Qiu, Y., Fu, B. J., Wang, J., \& Chen, L. D. (2001b). Spatial variability of soil moisture content and its relation to environmental indices in a semi-arid gully catchment of the Loess Plateau, China. Journal of Arid Environment, 49, 723-750.

Qiu, Y., Fu, B. J., Wang, J., \& Chen, L. D. (2003). Spatio-temporal prediction of soil moisture content using multiple-linear regression in a small catchment of the Loess Plateau China. Catena, 54, 173-195.

Ran, W., Xie, Y. S., \& Hao, M. D. (2008). Study on change of soil water in orchards of different planting-life in gully region of Loess plateau. Acta Agriculture Borealioccidentalis Sinica, 17(4), 229-233 (In Chinese with English abstract).

Schwinning, S., \& Sala, O. E. (2004). Hierarchy of responses to resource pulses in arid and semi-arid ecosystems. Oecologia, $141,211-220$

Shangguan, Z. P., \& Zheng, S. X. (2006). Ecological properties of soil water and effects on forest vegetation in the Loess Plateau. International Journal of Sustainable Development and World Ecology., 13, 307-314.

Vereecken, H., Kamai, T., Harter, T., Kasteel, R., Hopmans, J., \& Vanderborght, J. (2007). Explaining soil moisture variability as a function of mean soil moisture: a stochastic unsaturated flow perspective. Geophysical Research Letters, 34, L22402. doi:10.1029/2007GL031813.
Wang, Y. Q., Shao, M. A., \& Liu, Z. P. (2010a). Large scale spatial variability of dried soil layers and related factors across the entire Loess Plateau of China. Geoderma, 159(1-2), 99-108.

Wang, Y. Q., Shao, M. A., \& Shao, H. B. (2010b). A preliminary investigation of the dynamic characteristics of dried soil layers on the Loess Plateau of China. Journal of Hydrology, $381(1-2), 9-17$.

Wang, S., Fu, B. J., Gao, G. Y., Yao, X. L., \& Zhou, J. (2012). Soil moisture and evapotranspiration of different land cover types in the Loess Plateau, China. Hydrology and Earth System Sciences, 16, 2883-2892.

Wang, S., Fu, B. J., Gao, G. Y., Liu, Y., \& Zhou, J. (2013). Responses of soil moisture in different land cover types to rainfall events in a re-vegetation catchment area of the Loess Plateau, China. Catena, 101, 122-128.

Wei, W., Chen, L., Fu, B., Huang, Z., Wu, D., \& Gui, L. (2007). The effect of land uses and rainfall regimes on runoff and soil erosion in the semi-arid loess hilly area, China. Journal of hydrology, 335, 247-258.

Western, A. W., Zhou, S., Grayson, R. B., McMahon, T. A., Blöschl, G., \& Wilson, D. J. (2004). Spatial correlation of soil moisture in small catchments and its relationship to dominant spatial hydrological processes. Journal of Hydrology, 286, 113-134.

Wu, J. G., \& Hobbs, R. (2002). Key issues and research priorities in landscape ecology: an idiosyncratic synthesis. Landscape Ecology, 17, 355-65.

Yang, W. Z., \& Tian, J. L. (2004). Essential exploration of soil dissection in Loess Plateau. Acta Pedologica Sinica, 41(1), 1-6 (In Chinese with English abstract).

Zheng, H., Chan, F. L., Ouyang, Z. Y., et al. (2008). Impacts of reforestation approaches on runoff control in the hilly red soil region of Southern China. Journal of Hydrology, 356, 174-184.

Zhou, J., Fu, B., Gao, G., Lü, N., Lü, Y., \& Wang, S. (2015). Temporal stability of surface soil moisture of different vegetation types in the Loess Plateau of China. Catena, 128, 1-15. 